\title{
Retinopathy of prematurity: review of a four-year period
}

\author{
B P CATS' AND K E W P TAN
}

From the 'University Children's Hospital, the Wilhelmina Children's Hospital, Nieuwe Gracht 137, 3512 LK Utrecht, and the ${ }^{2}$ Royal Dutch Eye Hospital, FC Donderstraat 65, 3572 JE Utrecht, The Netherlands

SUMMARY For a four-year period the development of retinopathy of prematurity (ROP) was determined among neonates considered at risk of acquiring this condition. Fifty-six out of 249 premature infants developed some degree of ROP. Comparison of these infants with a group of 56 controls, admitted to hospital in the same period and matched for sex, birth weight, and gestational age, showed significant differences for sepsis, blood transfusions, and the period of oxygen monitoring in relation to the period of oxygen administration. The most consistent factor associated with the development of ROP was gestational age at the time of birth, though no gestational age group was entirely devoid of ROP. This suggests that screening for ROP should not be restricted to high-risk premature infants only.

During the last decade retinopathy of prematurity (ROP) has often been discussed in clinical paediatric papers. ${ }^{12}$ Improvements in technology now enable neonatologists to keep alive more neonates of very low birth weight (VLBW) and short gestational age. But although the opportunities for monitoring arterial oxygen tension have also improved, they have not stopped ROP from recurring. Its aetiology remains unknown. We studied the incidence of ROP in a four-year period and evaluated a number of risk factors in its pathogenesis.

\section{Patients and methods}

\section{PATIENTS}

From 1 April 1977 to 31 March 1981678 premature neonates were referred to the neonatal intensive care unit of the Wilhelmina Children's Hospital. Eye examinations were performed as soon as the babies' condition permitted them to be transferred from intensive care to the intermediate care ward.

We examined the following children: (a) all those born at a gestational age of under 32 weeks; (b) neonates of 32 and 33 weeks' gestation who had received more than $40 \%$ oxygen for longer than one day or who had been artificially ventilated; (c) premature infants of 34 or more weeks' gestation

Correspondence to Dr B P Cats. on artificial ventilation or high oxygen concentrations over a longer period.

ROP cases were matched with control patients of the same sex, birth weight, and gestational age admitted to hospital in the same period. If a child with ROP was one of identical twins of which the other one did not develop ROP, the latter served as control (three cases). We thus examined 249 surviving premature infants. ROP was present in $56(22 \cdot 8 \%)$.

\section{METHODS}

Throughout the study period all premature infants receiving any supplemental oxygen were given $10 \mathrm{mg}$ vitamin $\mathrm{E} / \mathrm{kg}$ body weight on admission and subsequently once a week until the oxygen treatment was discontinued. The oxygen concentration in the inspired air was measured by Hewlett-Packard oxygen meters or set by the oxygen-blenders on the artificial ventilation apparatus (Bourns BP 200).

During the first two years of the study $\mathrm{PaO}_{2}$ samples were drawn from all indwelling arterial lines at least once every four hours. This was continued during the last two years of the study, during which additional information was gathered by measuring transcutaneous $\mathrm{PO}_{2}\left(\mathrm{PtCO}_{2}\right)$ in as many children as long as possible (with a Hellige-Dräger electrode). Every two weeks children were selected for ophthalmic investigation according to the criteria mentioned above. Optimal mydriasis could be obtained in most 
children by giving them tropicamide and phenylephrine $\mathrm{HCl} 5 \%$ alternately every 10 minutes for $1 \frac{1}{2}$ hours. After the application of a local anaesthetic a baby-eyelid widener (Heiss) was introduced and indirect monocular ophthalmoscopy performed.

Follow-up investigations were performed as frequently as judged necessary in cases of proliferative ROP (until treatment or regression) or once every two weeks until discharge.

\section{Results}

ROP was found in 56 children out of 249 investigated (Table 1). General characteristics and some relevant clinical data of the ROP group and of the 56 nonROP controls are given in Table 2. Data relating to oxygen administration and monitoring are presented in Table 3.

The ROP stages found in our patients, according to the Patz's modification ${ }^{3}$ of Reese et al.'s classification (using RLF for retrolental fibroplasia) ${ }^{4}$ were: preRLF in $23(41 \cdot 1 \%)$, grade 1 in $23(41 \cdot 1 \%)$, grade 2 in

Table 1 Series of 551 surviving premature infants (out of 678 admissions) from which ROP and control cases have been selected

\begin{tabular}{llllll}
\hline & $n$ & Examined $(\%$ of $n)$ & ROP & $\begin{array}{l}\text { (\% of } \\
\text { examined } \\
\text { cases) }\end{array}$ \\
\hline 532 wks: & 169 & 156 & $(92 \cdot 3 \%)$ & 43 & $(27.6 \%)$ \\
$32-33$ wks: & 122 & 73 & $(39.8 \%)$ & 8 & $(11.0 \%)$ \\
$\geqslant 34$ wks: & 260 & 20 & $(7.7 \%)$ & 5 & $(25.0 \%)$ \\
\hline
\end{tabular}

$7(12 \cdot 4 \%)$, and grades $3-5$ (cicatricial forms leading to blindness) in $3(5 \cdot 4 \%)$. Fig. 1 shows the distribution of ROP cases in relation to the total of surviving premature infants and clearly points to an increasing risk with decreasing gestational age.

\section{Discussion}

The link originally suggested between oxygen and ROP has been challenged, as Silverman stated in 1982 , 5 and our study also casts doubt on it. Tables 2 and 3 show that in our ROP and non-ROP groups there are no significant differences between artificial

Table 2 General characteristics and clinical data of 56 ROP cases and controls

\begin{tabular}{lcc}
\hline & $R O P$ & Non-ROP \\
\hline $\mathbf{n}$ & 56 & 56 \\
Mean gestational age (wks) & $28 \cdot 7$ & $28 \cdot 9$ \\
Mean birthweight (grs) & 1140 & 1135 \\
Male : female & $27: 29$ & $27: 29$ \\
Artificial ventilation (n) & 26 & $31 \mathrm{NS}$ \\
Mean duration of ventilation (days) & $15 \cdot 6$ & $14 \cdot 5 \mathrm{NS}$ \\
Patent ductus arteriosus & 12 & $15 \mathrm{NS}$ \\
Bronchopulmonary dysplasia & 11 & $15 \mathrm{NS}$ \\
Pneumonia & 7 & $5 \mathrm{NS}$ \\
Sepsis (proved by blood culture(s)) & 19 & $8^{*} \mathrm{p}<0 \cdot 05$ \\
Exchange transfusion & & \\
$\quad$ (number of children) & 10 & $3 * \mathrm{p}=0 \cdot 06$ \\
Mean number of blood transfusions & & \\
$\quad$ in first two months & $6 \cdot 8$ & $4,7 \dagger \mathrm{p}<0 \cdot 005$ \\
\hline * $\chi^{2}$ test. & & \\
†Student's $t$ test. & & \\
NS $=$ not significant. & &
\end{tabular}

Table 3 Data pertaining to oxygen administration and monitoring

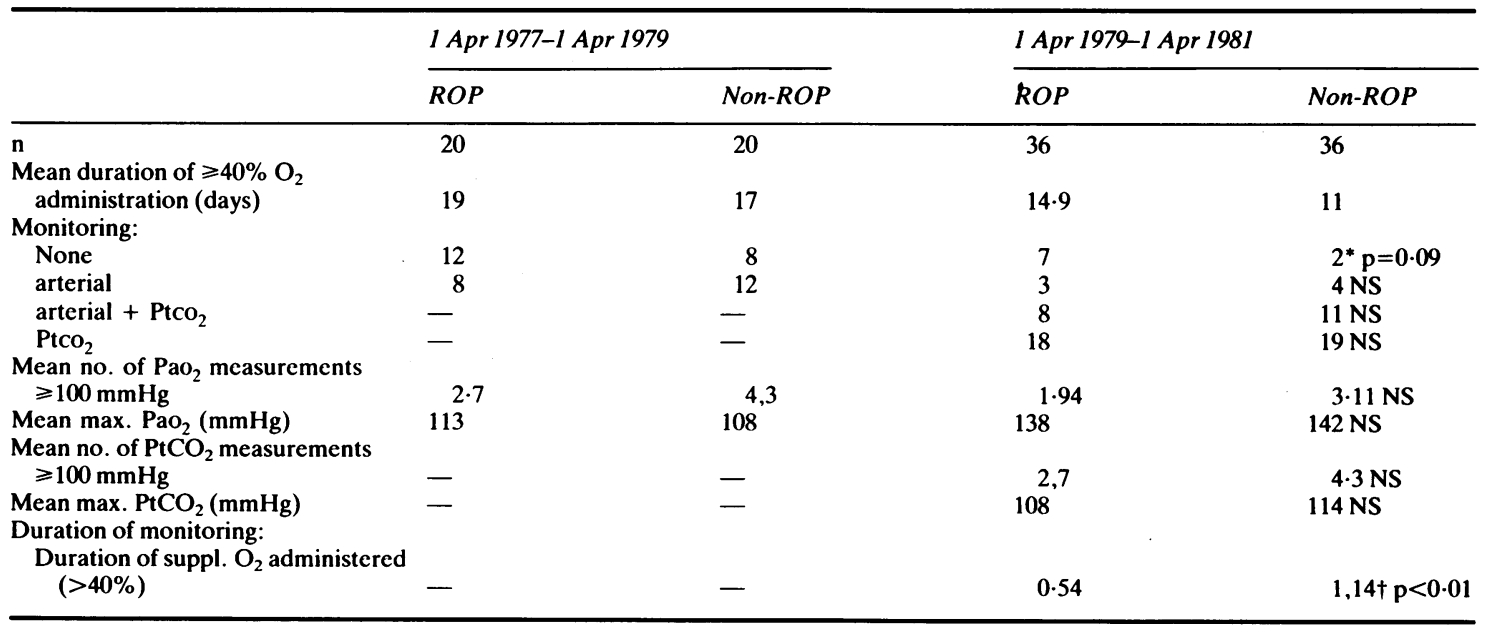

${ }^{*} \chi^{2}$ test.

†Student's $t$ test. 


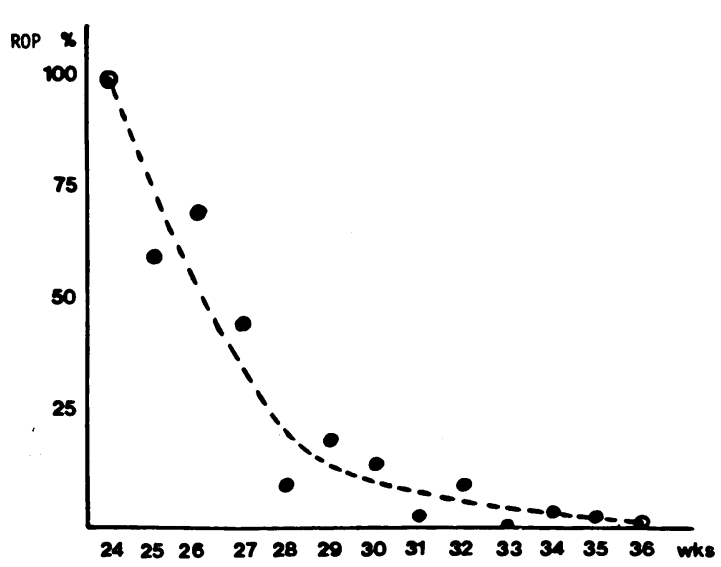

Fig. 1 Incidence of ROP as a percentage of survival according to gestational age.

ventilation and its duration, patent ductus arteriosus, bronchopulmonary dysplasia, mean duration of supplementory oxygen administration, and arterial and transcutaneous oxygen monitoring. Table 3 also shows that the introduction of $\mathrm{PtcO}_{2}$ measuring has at least had a beneficial effect with regard to the mean duration of oxygen administration, which has decreased from 19 to 14.9 days in the ROP group and from 17 to 11.0 days in the control group.

That oxygen cannot be eliminated as one of the important factors in ROP may be derived from the fact that a significant difference was found between the study group and the control group in the duration of monitoring. When dividing the duration of monitoring (either arterial and/or transcutaneous) by the number of days supplementary oxygen was administered $(\geqslant 40 \%)$, children from the ROP group were found to have been monitored for a significantly shorter time than those from the non-ROP group (ratios 0.54 and 1.14 respectively, Table 3 ).

Two other findings from our study may leave the oxygen theory at least partly intact. The first, the difference between exchange transfusions and blood transfusions between the two groups has been observed before ${ }^{6-8}$ and widely discussed. The second, although seeming not directly to point to oxygen, is the difference in sepsis incidence. This finding has been reported before ${ }^{y-12}$ but has evoked little comment.

It is our impression that the sepsis incidence may relate to the number of blood transfusions required in the neonatal period. In our patient groups there were no significant differences in number of children on artificial ventilation (and its duration) and number of children with arterial lines, which makes it unlikely that the difference in the number of blood transfusions was caused by increased blood sampling. However, increased haemolysis during sepsis periods may offer an explanation. With regard to oxygen radicals, it is now recognised that the oxidative burst which follows the activation of the superoxide generating systems occurs earlier and easier in newborn than in adult neutrophils. ${ }^{1314}$ When this mechanism operates throughout the whole body, and therefore also in the immature tissues and vessels of the eye, a link is established between sepsis with increased ocular toxicity and increased need for blood transfusions. On the basis of this concept we believe other investigators should consider sepsis as a possible risk factor in the development of retinopathy of prematurity.

The incidence of ROP in our patient population is comparable to the incidence mentioned by other authors in recent years. ${ }^{1516}$ The differing figures in different gestational age groups ( $<32$ weeks: $27 \cdot 6 \%$, $32-33$ weeks: $11 \%$, and $\geqslant 34$ weeks: $25 \%$ ) may be the result of the selection criteria we used. The increasing risk with decreasing gestational age, probably the most consistently encountered risk factor for ROP in the literature, is also seen in our data (Fig. 1).

However, the finding that among our premature infants no gestational age group is devoid of ROP raises the question of the need for all premature infants to be seen by an ophthalmologist. For higher risk groups, in all those centres providing neonatal intensive care, this should be mandatory in our view. For lower risk groups, it seems necessary to define a moment of optimal timing for ROP diagnosis. This would seem to be somewhere between the 5th and 10th week after birth, because those studying children from birth have rarely encountered ROP for the first time ${ }^{1017}$ before or after this period.

\section{References}

1 Gunn TR, Aranda JV, Little J. Incidence of retrolental fibroplasia. Lancet 1978; i: 216-7.

2 Tarkkanen A, Mustonen R. Retrolental fibroplasia: cases seen at the Helsinki University Eye Hospital 1956-1974. Acta Ophthalmol (Kbh) 1978; 56: 169-78.

3 Patz A. Retrolental fibroplasia. Surv Ophthalmol 1969; 14: 1-10.

4 Reese AB, King MJ, Owens WC. A classification of retrolental fibroplasia. Am J Ophthalmol 1953; 36: 1333-61.

5 Silverman WA. Retinopathy of prematurity: oxygen dogma challenged. Arch Dis Child 1982; 57: 731-3.

6 Aranda JV, Clark TE, Mannicllo R, Outerbridge EW. Blood transfusion: possible potentiating risk factor in retrolental fibroplasia. Pediatr Res 1975; 9: 633.

7 Bard H, Cornet J, Arquin, J, Doray BH. Retrolental fibroplasia and exchange transfusion (abstr.). Pediatr Res 1975; 9: 362.

8 Sacks LM, Schaffer DB, Anday EK, Peckham GH, DelivoriaPapadopoulos M. Retrolental fibroplasia and blood transfusion in very low-birth-weight infants. Pediatrics 1981; 68: 770-4.

9 Gunn TR, Easdown J, Outerbridge EW, Aranda JV. Risk factors in retrolental fibroplasia. Pediatrics 1980; 65: 1096-100.

10 Hittner HM, Godio LB, Rudolph AJ, et al. Retrolental fibroplasia: efficacy of vitamin $E$ in a double-blind clinical study of preterm infants. $N$ Engl J Med 1981; 305: 1365-71. 
11 Rothberg AD, Maisels JM, Bagnato S. et al. Outcome for survivors of mechanical ventilation weighing less than $1250 \mathrm{~g}$ at birth. J Pediatr 1981; 98: 106-11.

12 Yu VYH, Hookham, DM, Nave JRM. Retrolental fibroplasiacontrolled study of 4 years' experience in a neonatal intensive care unit. Arch Dis Child 1982; 57: 247-52.

13 Hammerschmidt DE, Jacobs HS. The stimulated granulocyte as a source of oxygen toxicity compounds in tissue injury. In: Autor AP, ed. The pathology of oxygen. New York: Academic Press, 1982.
14 Strauss RG, Snyder EL. Activation and activity of the superoxide-generating system of neutrophils from human infants. Pediatr Res 1983; 17: 662-4.

15 Phelps DL. Retinopathy of prematurity: an estimate of vision loss in the United States. Pediatrics 1979; 67: 924-5.

16 Kalina RE, Karr DJ. Retrolental fibroplasia. Experience over two decades in one institution. Ophthalmology (Rochester) 1982; 89: $91-5$.

17 Palmer EA. Optimal timing of examination for acute retrolental fibroplasia. Ophthalmology (Rochester) 1981; 88: 662-8. 